\title{
Electrodynamical Coupling of Earth's Atmosphere and Ionosphere: An Overview
}

\author{
A. K. Singh, ${ }^{1}$ Devendraa Siingh, ${ }^{2}$ R. P. Singh, ${ }^{3}$ and Sandhya Mishra ${ }^{1}$ \\ ${ }^{1}$ Department of Physics, University of Lucknow, Lucknow 226007, India \\ ${ }^{2}$ Indian Institute of Tropical Meteorology, Pune 411-008, India \\ ${ }^{3}$ Physics Department, Banaras Hindu University, Varanasi 221005, India
}

Correspondence should be addressed to A. K. Singh, aksphys@gmail.com

Received 24 March 2011; Revised 31 July 2011; Accepted 9 September 2011

Academic Editor: Lucilla Alfonsi

Copyright (C) 2011 A. K. Singh et al. This is an open access article distributed under the Creative Commons Attribution License, which permits unrestricted use, distribution, and reproduction in any medium, provided the original work is properly cited.

\begin{abstract}
Electrical processes occurring in the atmosphere couple the atmosphere and ionosphere, because both DC and AC effects operate at the speed of light. The electrostatic and electromagnetic field changes in global electric circuit arise from thunderstorm, lightning discharges, and optical emissions in the mesosphere. The precipitation of magnetospheric electrons affects higher latitudes. The radioactive elements emitted during the earthquakes affect electron density and conductivity in the lower atmosphere. In the present paper, we have briefly reviewed our present understanding of how these events play a key role in energy transfer from the lower atmosphere to the ionosphere, which ultimately results in the Earth's atmosphere-ionosphere coupling.
\end{abstract}

\section{Introduction}

The atmosphere of the Earth is a layer of gases surrounding the Earth that is retained by Earth's gravity. The atmosphere protects life on the Earth by absorbing the ultraviolet solar radiation, warming the surface through heat retention (greenhouse effect), and reducing temperature extremes between day and night. Based on temperature distribution, atmosphere is divided into the troposphere, stratosphere, mesosphere, and thermosphere. The temperature in the thermosphere remains almost constant (Figure 1) [1]. The stratosphere and mesosphere regions are also grouped as the middle atmosphere. The region above the middle atmosphere is called the upper atmosphere where solar radiation and other sources ionize the neutral constituents forming plasma of ions and electrons. The region extending from the mesosphere to the thermosphere is called ionosphere where plasma dynamics is controlled by the collisions between the ionized particles and neutrals as well as between the ionized particles themselves. The region above the ionosphere is known as the magnetosphere. In this region, charged particles dynamics is controlled by the Earth's magnetic field because the density collision frequency is very low. There is no sharp boundary between the upper ionosphere and the lower magnetosphere region.

The ionosphere system is mainly controlled by various external sources of forcing and number of mechanisms operative in the system to convert, transport, and redistribute the input energy. Solar extreme ultraviolet (EUV) radiation and particle energy from the sun in the form of precipitating solar wind plasma energetic particle influence from the above, while tides, planetary waves, gravity waves, electromagnetic waves in wide frequency range, turbulence, convection, and so forth from the below. Even processes taking place below/on/above the surface of the Earth also affect the ionosphere and its processes. In fact, lower atmosphere/middle atmosphere/upper atmosphere (ionosphere)/magnetosphere acts as a multi-coupled system. The coupling occurs mainly through the dynamical, chemical, and electrical processes.

The ionosphere reacts to various phenomena such as lightening discharges, functioning of high-power transmitters, high-power explosion, earthquakes, volcano eruptions, and typhoons through a chain of interconnected processes in the lithosphere-atmosphere-ionosphere interaction system. Thunderstorms play a major role in transferring energy from the atmosphere to the ionosphere [3] and in establishing 


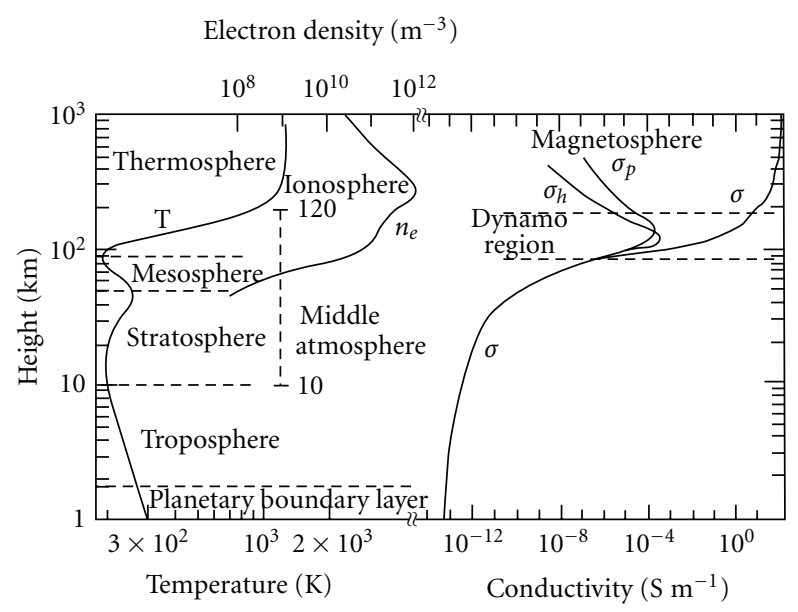

FIGURE 1: Variation of temperature, electron density and electrical conductivity of various atmospheric layers, after [1].

electrical coupling between atmosphere and ionosphere through the global electric circuit (GEC). The Earth's surface has a net negative charge, and there is an equal and opposite positive charge distributed throughout the atmosphere above the surface. The electrical structures of the lower atmosphere, GEC, and conductivity profile shown in Figure 1 are deeply influenced by cosmic ray flux [4], high-power transmitted waves [5-7], and earthquakes [8]. Lightening-generated whistler mode waves scatter radiation belt trapped electrons which precipitate into the lower ionosphere and result into the additional ionization and formation of ionospheric inhomogeneities $[9,10]$. The powerful high-frequency transmitted waves produce ionospheric heating which, in turn, causes generation of ultra-low-frequency (ULF) and extremely low-frequency (ELF) waves [11], the formation of very low-frequency (VLF) ducts and other types of inhomogeneities $[12,13]$, the acceleration of ions, and the excitation of atmospheric emissions in different spectral bands [14]. The effects of these processes on the GEC (including the ionosphere) are not yet fully understood.

The convective activity in thunderstorms produces gravity waves which propagate to the lower ionosphere and deposit energy and momentum through the process of breaking and absorption and may help in the initiation of sprites and other transient luminous events (TLEs) [1517]. The converse problem is the generation of acoustic gravity waves by sprites and other TLEs. The thermal energy deposited in the neutral atmosphere within a sprite volume $\left(\sim 10^{4} \mathrm{~km}^{3}\right)$ during short $(<1 \mathrm{~ms})$ duration may produce an impulsive pressure pulse that propagates laterally outward as an acoustic/gravity wave [18]. The energy deposited by a large sprite could be as large as $\sim 1$ GJ [19]. The acoustic gravity wave causes spatial and temporal modulation of plasma density and electric conductivity in the ionospheric E layer. The associated wave instability causes generation of related field-aligned currents and plasma density irregularities in the upper ionosphere [20]. The satellite observations anomalous DC electric field, ULF magnetic pulsations, small scale plasma inhomogeneities, and correlated ELF emissions
[21] may be considered as experimental evidence for these processes. However, the full knowledge of the interconnection between gravity waves and TLEs remains unresolved.

The purpose of this paper is to review briefly the present understanding of the link between most of the processes operative in the lower atmosphere and their electrodynamic coupling with the ionosphere. After this introduction, Section 2 deals with a more detailed description of physics of the atmosphere-ionosphere coupling. Various coupling processes including AC and DC phenomena are discussed in Section 3. Brief summary is given in Section 4 with some discussions.

\section{Physics of Earth's Atmosphere-Ionosphere (AI) Coupling}

Thunderstorms and lightning discharges are the main sources of electromagnetic and electrostatic energy in the Earth's atmosphere. Electrostatics involves the buildup of charge on the surface of objects due to contact with other surfaces. Although charge exchange happens whenever any two charged surfaces contact and separate, the effects of charge exchange are usually only noticed when at least one of the surfaces has high resistance to electrical flow. In thunderstorms, a rapid vertical rearrangement of deep air layers takes place. Large processes promote, shape vertical and horizontal air motions, and processes within storms control the development of rain and strong local winds. Vigorous vertical air currents and thunderstorms are a consequence of excessive warmth and moisture at low altitudes.

Thunderstorm consists of a cluster of clouds. Electrical charges generate and separate during the developmental stage of thunderstorm and are neutralized during lightning discharges. Numerous processes operating within the environment of a mature convective cloud with varying effectiveness and time dependencies affect cloud electrification $[22,23]$. The charging of thunderstorms can be discussed as inductive charging or noninductive charging. An inductive process requires preexisting electric fields to induce charges on a particle so that when it rebounds from another particle, charge is separated and the field is enhanced. In the atmosphere, the fair-weather electric field resulting from positive charges in the atmosphere and negative charges on the ground could be considered as the preexisting field. However, there are experimental results from airborne instruments which require some other processes of charging [22]. Noninductive processes are independent of the presence of an external electric field. In an ordinary thundercloud, the smaller ice crystals are charged positively and move upward, whereas larger graupel particles charged negatively descend relative to the smaller particles under the action of gravity. This is the normal situation, depending on the prevailing conditions of temperature, liquid water content, and mixing in the thunderstorm. Situation in thunderstorm is quite variant, and charging process may not remain as discussed above [24]. To better understand these phenomena, further investigations 


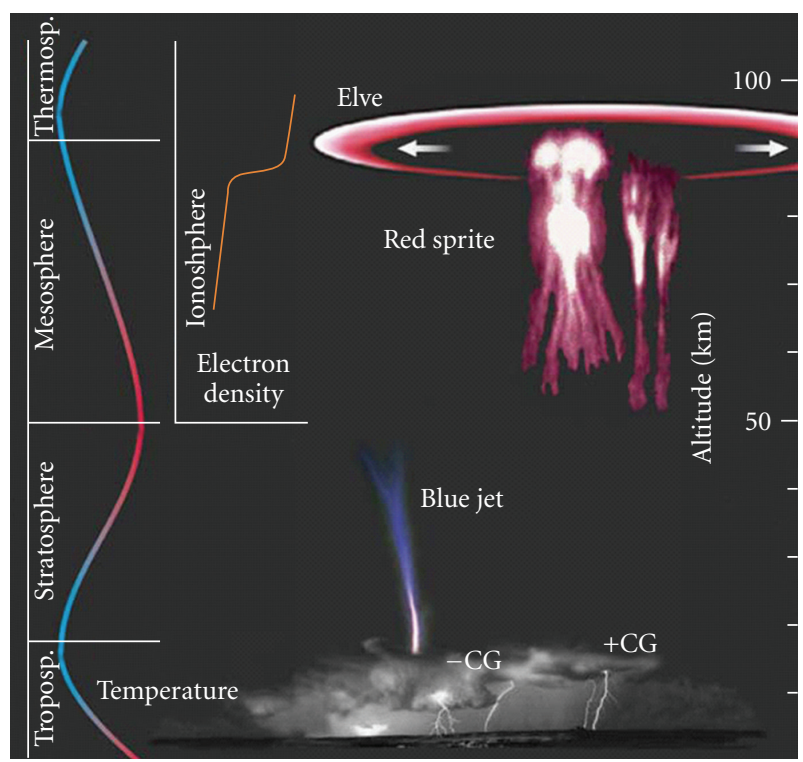

FIGURE 2: Depiction of various optical events in the atmosphere and the altitude at which they occur, credit [2].

involving both precise measurements of time development of electric field inside the cloud and simulations are required.

The charge buildup during the active period of a thunderstorm ultimately results into lightning discharge either through the processes of dielectric breakdown or runaway breakdown [29-32]. The electric field computation favours runaway breakdown mechanism [33]. However, discharge processes are not fully understood, and further observations and works are required. Lightning discharge creates charge imbalance in the cloud/thunderstorm, and as a result upward propagating quasi-electrostatic field initiates from the upper charge-layer of thunderstorm. This quasi-electrostatic field connects troposphere with the stratosphere and the lower ionosphere for a very short duration. There are about 40 to 100 lightning discharges occurring every second. Apart from the upward propagating quasi-electrostatic fields, lightning discharge current generates intense electromagnetic pulses of 20 GW peak powers [34] which may cause significant ionospheric disturbances because of the heating and acceleration of electrons, production of ionization, optical emissions, and so forth.

The upward propagating quasi-electrostatic causes transient luminous events (sprites, blue jets/gigantic jets, elves, etc.) in the stratosphere and the mesosphere which influence the lower ionosphere with additional ionization and formation of ionospheric inhomogeneities and has motivated scientists all over the world to reexamine our understanding of the electrical processes and properties of the atmosphere. Figure 2 shows the variety of transient luminous events and the typical altitude at which they occur. Sprites may occur in cluster of short-lived $(\sim 50 \mathrm{~ms})$ two, three, or more carrotshaped emissions of $\sim 1 \mathrm{~km}$ thickness over a horizontal distance of $50-100 \mathrm{~km}$, with the separation between sprite elements of $\sim 10 \mathrm{~km}[2,35]$. The upper portion of the sprites is red, with wispy, faint blue tendrils extending to $40 \mathrm{~km}$ or at time as low as the cloud top and bright region is in the altitude range $65-85 \mathrm{~km}$ [35]. They typically last for $5-50 \mathrm{~ms}$ and may take the form of one or more vertical columns of a few hundred meter radius for the smaller column sprites or large jellyfish-shaped structures of tens of kilometers of radius and extending from the ionosphere Dregion almost down to the thunderstorm cloud tops [2, 35]. The knowledge gained from laboratory experiment of gas discharges at subatmospheric pressure has been used to understand sprite spectroscopy and associated phenomena [25]. Figure 3 shows broad identical spectral characteristics of light of positive column of the laboratory tube and sprites [25]. The difference in spectral characteristics may be due to difference in applied electric field, gas pressure, and gas composition in the mesosphere and gas tube discharges. Physical processes associated with sprites and other optical events are also associated with thunderstorm activity in the troposphere and are thought to result in the gradual buildup of conductivity changes in the lower ionosphere [36]. Liszka [37] suggested the generation of infrasound waves by sprites, whose signatures were detected by a network sensors in Sweden [38]. The shape of the chirp signature in the spectrograms of infrasound can be explained by the horizontal size of the sprite [39]. Neubert et al. [40] have concluded that sprite detection by infrared is an attractive alternative to optical detection, because it is not limited by clear viewing condition or by the absence of daylight.

Elves are concentric rings of optical emissions propagating horizontally outwards at the bottom edge of ionosphere between $75-95 \mathrm{~km}$ altitudes caused by the electromagnetic pulse radiated by the cloud to ground lightning discharge current of either polarity. Elves produce average electron density enhancements of 210-460 electrons $\mathrm{cm}^{-3}$ over large (165-220 km diameter) circular regions having an assumed $10 \mathrm{~km}$ altitude extent $[41,42]$ and hence produce perturbation in electrical conductivity of the mesosphere which can be evaluated by measuring changes in the amplitude of VLF waves $[43,44]$ from transmitters and propagating in the Earth-ionosphere waveguide. Mika [45] has discussed experimental data in which the incident VLF transmitter signal seems to be scattered from horizontally extended diffuse regions of electron density enhancements, most likely associated with halos or diffuse regions of the upper part of carrot sprites, rather than small-scale streamers observed at lower altitudes. The electromagnetic pulse (EMP) generating elves also create ionization [46, 47], which depends on its intensity. The individual contributions of different components of constituent gas to the optical emissions of sprite/elves are not known. An attempt should be made to investigate lightning chemistry and energetics in the region of sprites/elves. This may require future studies using a large number of narrow band filters in optical observations and kinetic modeling in theoretical analyses.

The transient luminous events provide a link between tropospheric processes in the thunderstorms and mesospheric processes in the upper atmosphere, and their studies also promise to improve our understanding of the elusive mesosphere, perhaps the least understood layer of Earth's atmosphere. Hiraki et al. [48] suggested that sprites may 


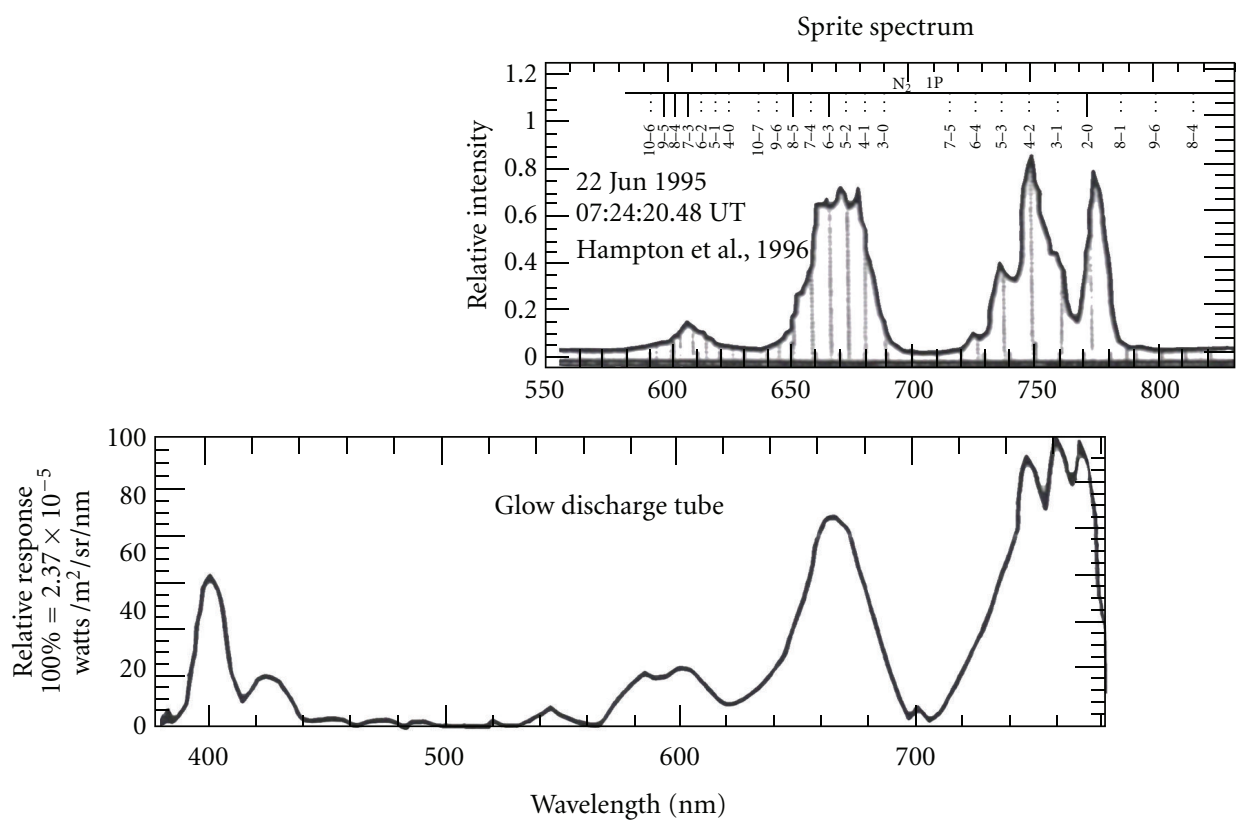

(a)

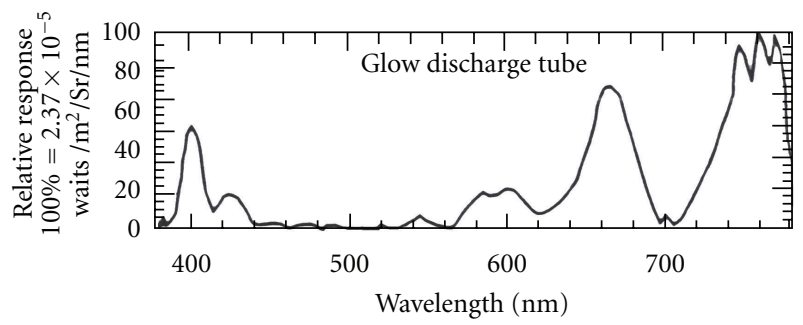

(b)

Figure 3: Comparison of optical spectra for (a) sprite in the mesosphere and for (b) the positive column of large glow discharge tube, after [25].

change the concentration of NOx and HOx in the mesosphere and lower atmosphere. These chemical changes have impact on the global cooling or heating in the middle atmosphere [49-51]. Nitrogen oxides are critical components of the troposphere which directly affect the abundance of ozone and hydroxyl radicals [52]. Ozone absorbs solar ultraviolet radiation and controls the dynamic balance of the atmosphere. NOx creates ozone in the troposphere and destroys it in the stratosphere and mesosphere and thus affects the climate. This area of investigation remains unexplored.

Lightning generated whistler mode waves propagate along geomagnetic field lines without appreciable attenuation and thus connects troposphere with the ionosphere and the magnetosphere. Whistler mode waves while propagating through the equatorial region of the magnetosphere interact with the Earth's radiation belt trapped electrons and cause their precipitation in the form of plasma inhomogeneities in the high-latitude lower ionosphere. Such a type of coupling has been confirmed in ground-based observations [53], balloon measurements [54], rocket experiments [55, 56], and satellite observations $[57,58]$.
Thunderstorms and lightning discharges form the major current source in GEC, essential features of which are shown in Figure 4 [26]. Solar wind interactions with the Earth's magnetic generate additional current [59], and potential gradient modulation may arise from coupling of geomagnetically-induced changes in the magnetospheric dynamo through the global circuit. Precipitations from electrified clouds are also current driver [60]. The total current flowing in the atmospheric GEC is $\sim 1-2 \mathrm{kA}$ [27]. A realistic model of equivalent circuit with capacitors, resistors, and switches is shown in Figure 5 [28]. A switch is closed for a short time if a certain type of discharge occurs. For example, switch $S_{2}\left(S_{3}\right)$ closes for $\sim 1 \mathrm{~ms}$ when positive (negative) cloud to ground discharge occurs for a particular storm. The switch $S_{1}$ closes for a few $\mathrm{ms}$ when a sprite occurs above a particular thunderstorm and fair-weather time constant, $r C \sim 2 \mathrm{~min}$ $(r \sim 200$ ohms, $C \sim 0.7 \mathrm{~F})$. Generators act over $<1 \%$ of Earth's surface, and remaining $~ 99 \%$ of the Earth's surface region acts as a load on the circuit. The total current (I) flowing in the circuit is $\sim 1 \mathrm{kA}$ [28]. The GEC is based on the concept that the quantity of electric charge has to be conserved in the Earth's atmosphere-ionosphere-magnetosphere 


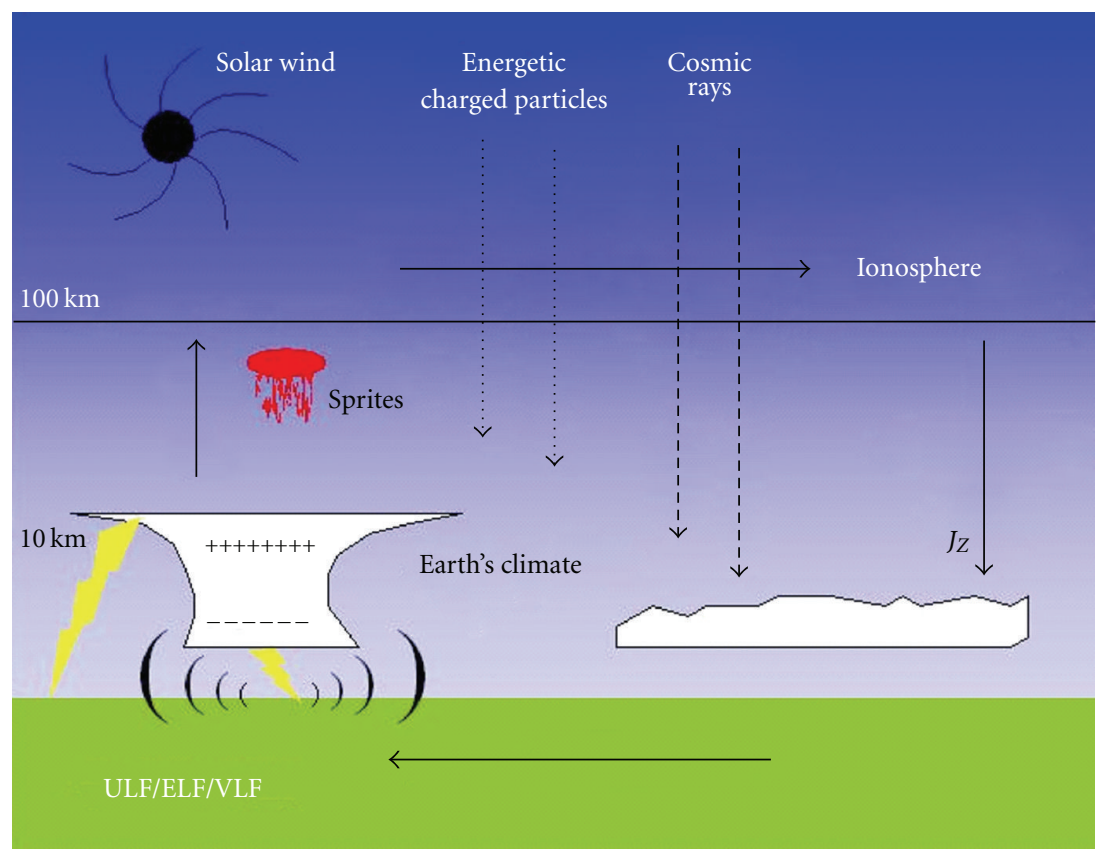

Figure 4: Essential features of the global atmospheric electric circuit [26, 27].

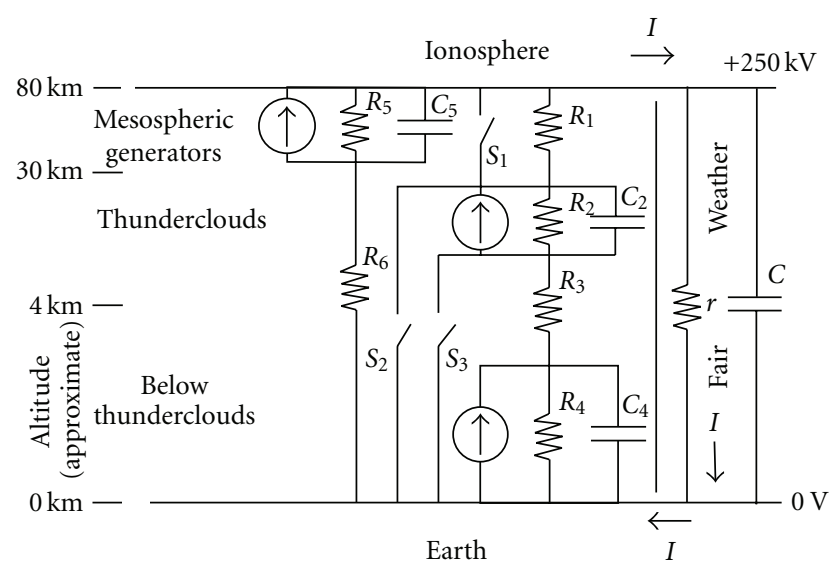

Figure 5: Diagram showing a schematic equivalent circuit for global electric circuits, credit [28].

system, that electric currents redistribute charge and that the electric currents are continuous.

The power supplied by thunderstorms is insufficient to maintain a field of magnitude observed in fair-weather regions. Rycroft et al. [61] included the generator associated with electrified clouds in the GEC model; this was found to be of the same magnitude as that due to thunderstorms. The optical phenomena occurring in the upward branch of the GEC above the thunderstorms are likely to influence only the upper atmosphere conductivity. Since they occur much less frequently (only one sprite out of 200 lightning) because of their association with intense lightning discharges $[50,62]$, their contribution to the ionospheric potential is very small [61]. The gigantic jets transport large quantities of negative charge discharging the atmospheric capacitor [63-66] whose effects on the ionosphere and GEC have not yet been modeled. The role of sprite/TLE events on the flow, charging/discharging of GEC, modification of electric fields near the Earth's surface remains unanswered. Since optical emissions could change electrical properties of the atmosphere and influence processes related with weather and climate, intense research activity in this area is required.

The earthquakes affect the electrodynamics of the atmosphere through the generation of electric and magnetic fields with crustal deformation, fault-failure-related piezomagnetism, stress/conductivity, electrokinetic effects, charge generation processes, thermal remagnetization, and demagnetization effects, and so forth [67]. These processes in the Earth's lithosphere relate with disturbances in the atmosphere and ionosphere. Sorokin et al. [8] discussed the processes forming the electrodynamic model of the effect of seismic and meteorological phenomena on the ionosphere. Radioactive substances and charged aerosols injected into the atmosphere modify the altitude profile of conductivity, generation of external currents, perturbation of electric field, and current in the ionospheric layer. As a result, Joule heating of the ionosphere and instability of acoustic gravity waves take place, which manifests in the formation of horizontal inhomogeneities of ionospheric conductivity. Finally, excitation of plasma density fluctuations and ULF/ELF emissions in the ionosphere, generation of field aligned currents and plasma layers, upward plasma transport, and modification of $\mathrm{F}_{2}$-layer, and change in the ion composition of the upper ionosphere take place $[68,69]$. These changes may also affect the GEC and the Earth's climate which remains a challenging problem to be solved. Figure 6 shows a schematic diagram which can be used to 


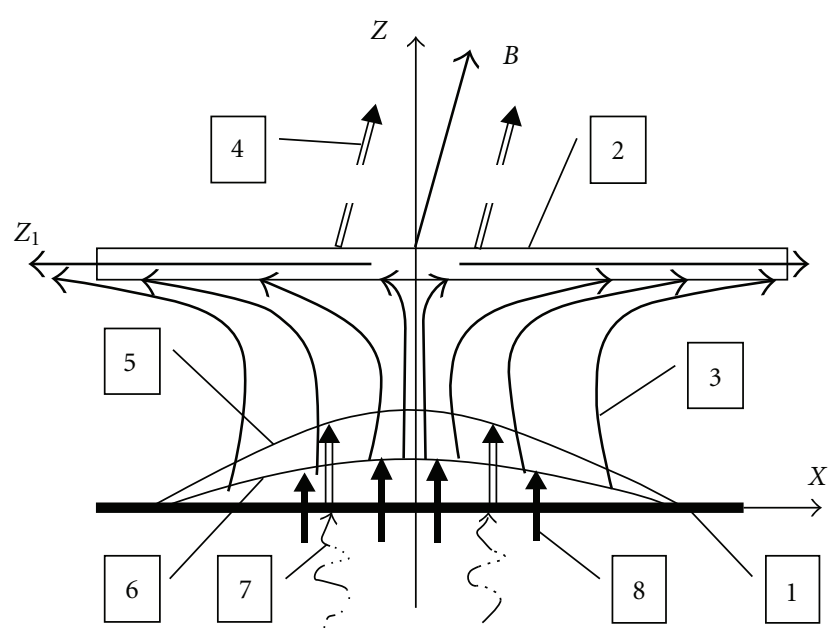

FIGURE 6: Schematic model used for the calculation of electric field due to the injection of charged aerosols in the atmosphere-ionosphere circuit. 1-Earth's surface, 2-ionosphere, 3 -conducting current in the atmosphere and the ionosphere, 4 field-aligned current, 5-zone of upward convection of charged aerosols and external electric current formation, 6-zone of perturbation of atmospheric conductivity induced by radioactive elements emanation, 7 - charged aerosols moving upward with soil gases, 8-radioactive elements emanation, credit [3].

compute external currents and enhancement of electrical conductivity in the lower atmosphere that causes an increase in the electric field in the ionosphere due to the injection of charged aerosols and radioactive elements from the solid Earth during earthquakes [3].

There are some other complex processes showing multiple scales of variability. Turbulent mixing and eddy diffusion are few other ways of transport from below. They control the relative abundances of atmospheric species in the mesosphere whose distribution tends to be independent of altitude. As part of a physical mechanism, the influence of internal atmospheric waves may be considered. The upward propagation of internal atmospheric waves (planetary waves, tides, and gravity waves) from the troposphere and stratosphere is an essential source of energy and momentum for the thermosphere and ionosphere. Weaker mesospheric gravity waves will lead to stronger winds in the upper atmosphere, which in turn will affect the ability of planetary waves to propagate, producing an additional feedback route [70]. Of course, the study of internal waves is the province of meteorology, a discipline that has enjoyed a long and independent development of its own and has its own complicated problems, sufficiently different from ionospheric physics that the two are regarded as separate but neighbouring disciplines. However, the internal waves launched by weather fronts or any other sources in the troposphere and stratosphere sometimes appear to be capable of penetrating into the ionosphere, where they dissipate most of their energy. The leakage of wave energy from the troposphere and stratosphere at least up to $100-115 \mathrm{~km}$ was introduced as coupling from below [71] and is considered as a mechanism of the meteorological influence on the ionosphere.

\section{Various Coupling Processes}

Thunderstorms directly couple the atmosphere and the ionosphere. Potential difference between the ionosphere and the Earth is maintained by thunderstorms' pumping action of lightning discharges and electrified clouds. In the Earthionosphere cavity, the electric field and the conduction current in the lower atmosphere are primarily controlled by ions. Ions have the characteristic parameters such as mobility, lifetime, and generation rate that vary with altitude. In recent years, some progress has been made towards understanding thunderstorm and lightning $[22,72,73]$. The essential factors in marinating the lightning discharge is the gas breakdown caused by the stored electrostatic charge in the leader head. This extends the channel into new regions. General models of the cloud charge distribution are based on electric field measurements inside a thundercloud and on the ground below the thunderstorm [75]. Earlier, an oversimplified tripolar charge structure consisting of a negative charge in the middle of the cloud, a positive charge above it, and a smaller positive charge below were widely used. Later on, a screening negative charge on the upper cloud boundary was considered [76] which are depicted in Figure 7. In the convective updraft zone of a matured thunderstorm, usually four charge layers are found and outside updraft convection region at least six charge layers are seen. Forward and rearward anvils typically contain positive charges screened with negatively charged layers. However, this model does not represent super cell storms which usually have dominant positive charge at mid-levels in place of the typical main negative charge region [77], that is, super cell storms have "inverted polarity" charge structure, and they produce mainly positive cloud-to-ground lightning. The proposed model (Figure 7) is based on balloon soundings of convective region of storms that occurred in a limited portion of the lower midlatitudes. Its validity for storms in other mid-latitude regions, the tropics, and high latitudes are yet to be tested because of scarce in situ data.

The global electric circuit (GEC) links the electric field and current flowing in the lower atmosphere, ionosphere, and magnetosphere forming a giant spherical condenser $[50,59,78]$, which is charged by thunderstorms and other generators to a potential of several hundred thousand volts [79] and drives a vertical current through the fair weather atmosphere's columnar resistance $\left(\sim 1.3 \times 10^{17} \mathrm{ohm} \mathrm{m}^{-2}\right)$. Recently, Stolzenburg et al. [30] examined electric field data of 32 balloon soundings through MCS (mesoscale convective system) stratiform regions and inferred that for 15 cases the stratiform cloud was charging the GEC, while in the other 17 cases the cloud was discharging the circuit. Thus, the overall effect of MCS on GEC could be very large or very small. Davydenko et al. [80] modeled the quasi-electrostatic electric fields and currents inside and near an isolated MCS producing positive discharges and also sprites and showed that the large $(\sim 25 \mathrm{~A})$ cloud-to-ground, quasi-DC current discharges the GEC. Their full impact on the GEC and that of the positive cloud-to-ground flashes which they initiate remains to be quantified. The vertical current causes weak electrification of stratified clouds [81] and produces a vertical 


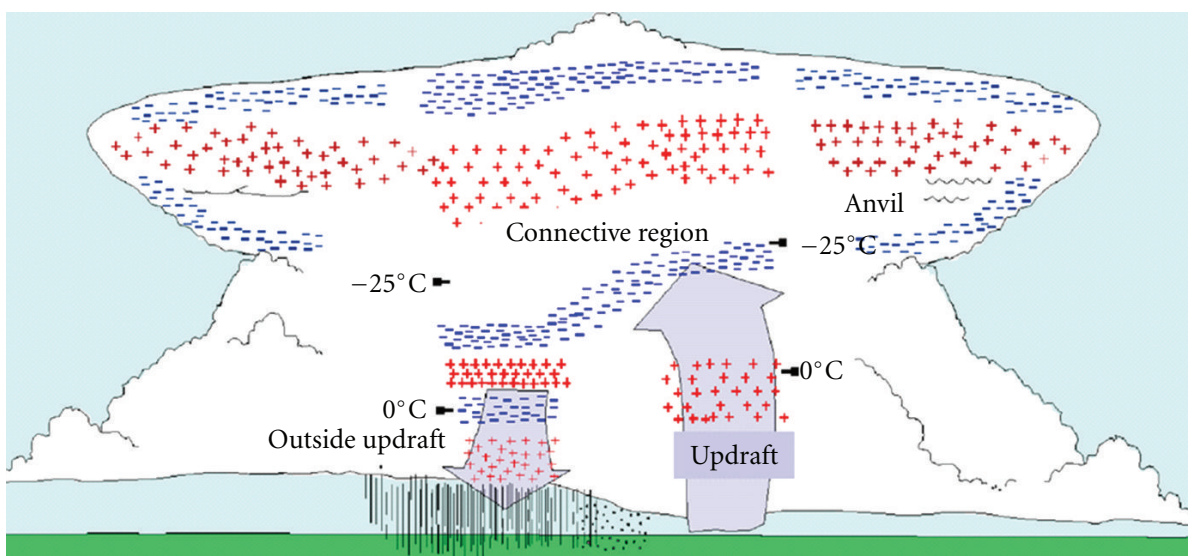

Figure 7: Conceptual model of the charge structure within an idealized isolated, mature thunderstorm based on 49 balloon sounding through different clouds, credit $[22,76]$.

potential gradient in the atmosphere near the Earth's surface. The circuit is closed by a horizontal current flowing through the highly conducting Earth and the ionosphere, and by vertical currents from the ground into the thunderstorm and from the top of the thunderstorm to the ionosphere.

3.1. AC Phenomena. Thunderstorm is the main source of both AC and DC coupling of the lower atmosphere and the ionosphere through lightning discharges. Return stroke of lightning discharge produces a pulse of radio energy containing waves from a few $\mathrm{Hz}$ up to several $\mathrm{MHz}$. These signals propagate in the Earth-ionosphere wave guide over long distances (several thousand $\mathrm{kms}$ ). The lowest frequencies of the discharge spectrum are ELF $(3-3000 \mathrm{~Hz})$ waves which excite the Earth-ionosphere cavity at 8, 14, $20,26, \ldots . \mathrm{Hz}$, commonly known as Schumann resonances [82]. Resonances are being continuously excited because lightening is always occurring all over the world. Recent interest in Schumann resonance studies arose because the charge movement change (CMC) of the parent lightening discharge can be evaluated by measuring the contribution of each mode in the resonance pattern which has been used in TLEs studies [83-85]. Thus, coupling between the atmosphere near the surface of the Earth and the ionosphere can be studied on the time scale ranging from a fraction of second to less than $1 \mu \mathrm{s}$.

Some of the wave energy from lightning generated wave spectra propagates into the ionosphere and magnetosphere system, where it interacts with ambient plasma particles and affects the global ionospheric/magnetospheric energy budget. Waves in the very-low-frequency (VLF, 3-30 kHz) range propagate in the ducted mode along the geomagnetic field lines [86] and cause magnetospheric electron precipitation into the lower ionosphere, leading to D-region conductivity modification $[87,88]$. Unducted VLF wave propagation can also take place [89]. Precipitating charged particles may participate in dissociation and ionization processes. There are VLF signatures of ionospheric disturbances associated with sprites $[29,43,90,91]$.

Hydromagnetic waves in the ultra-low-frequency (ULF, $<3 \mathrm{~Hz}$ ) propagate through the magnetosphere in one of several different modes at speeds considerably less than the speed of light. These waves interact with the ions in the ionosphere and magnetosphere. ULF waves sometimes are called magnetospheric analogues of seismic waves, which enable remote sensing of volumes from point measurements [92]. Waves in the frequency range $\sim 0.1-5 \mathrm{~Hz}$ also excite the ionospheric Alfven resonator (IAR) [93, 94] which is centered on the maximum of the ionospheric $\mathrm{F}_{2}$-region where the refractive index for Alfven waves has a maximum value. The variation of spectral resonance structure of the IAR over a solar cycle has also been studied [95]. The boundaries of IAR are at $\sim 1000 \mathrm{~km}$ altitude in the topside ionosphere and in the E-region ionosphere.

The ULF-VLF electric fields were detected up to topside ionosphere over powerful Pacific Ocean typhoons [96]. However, details of the mechanisms are not yet known. Ionospheric heating due to lightning electromagnetic pulses was considered and modeled $[97,98]$. Large amplitude radio waves from ground-based transmitters at VLF [99] and high frequency $(\mathrm{HF}, 3-30 \mathrm{MHz})$ [100] have been used to study ionospheric heating and modification. The associated phenomena include perturbations of electron density and temperature (increase of ionization at E-region, E-sporadic occurrence, increase of temperature, and electron density in F-region), excitation of electrostatic wave turbulence, and enhanced optical emissions.

The heating of the lower thermosphere by lighteninggenerated electromagnetic pulses may result into electrical breakdown and production of sprites and other optical emissions [101, 102]. The more exotic relativistic runaway (avalanche) breakdown mechanism, which can produce bremsstrahlung and gamma-rays radiations, has also been proposed and discussed [31, 103, 104]. Rowland [47] had reviewed both mechanisms. The two processes are coupled in the sprite streamer: the thermal discharge produces a beam of relativistic seed electrons that allow ignition of runaway relativistic discharge [105]. The thundercloud electric field at the lower thermosphere altitude is very transient, $\sim 1-10 \mathrm{~ms}$, consequently the observed sprite and halo phenomena are also of transient nature. The conventional breakdown 
mechanism explains most observations of sprites and their associated phenomena. Gerken and Inan [106] indicated that relatively faint and diffuse sprites confined to lower altitude could be associated with very high-peak currents and short-duration lightning discharges. Adachi et al. [107] reported that the number of columns in a sprite event was proportional to the peak current intensity of positive cloud-to-ground discharges, which was not corroborated by the results of van der Velde et al. [108]. This suggests a complex relationship between sprite morphology and incloud lightning processes, which are not yet fully understood.

Streamers associated with sprites are needle-shaped filaments of ionization and are driven by enhanced electric fields due to charge separation in their head, and the sign of the charge in head determines polarity of streamers. Liu and Pasko [109] have modeled preionization ahead of the streamer by ionizing ultraviolet photon originating in the streamer head. Thus, they consider photo ionization to be important in determining the propagation and branching of sprite streamer. The presence of inhomogeneities in the background density could also be helpful in the formation of streamers [110]. They have also explained the polarity asymmetry in triggering sprite streamer. Blue jets sometimes appear at the top of an energetic thundercloud and propagating upwards with a vertical velocity of $\sim 100 \mathrm{~km} \mathrm{~s}^{-1}$ to a maximum altitude of $\sim 40 \mathrm{~km}$ or so. These are believed to be a positive streamer formed in the upward quasi-electrostatic field above the cloud [63, 101]. Many streamers originate from the surface of the leader head (both positive and negative).

Pasko and George [111] have modeled the branching streamers as fractal tree growing in three dimensions. Pasko et al. [112] reported an unusual blue jet above a relatively small thunderstorm cell in Puerto Rico, and propagating up to $\sim 70 \mathrm{~km}$ altitude. Its characteristics above $42 \mathrm{~km}$ resembled those of sprites but having longer duration. This shows that an electrical contact was made between the top of the thunderstorm and the lower ionosphere. Gigantic jets extend from the cloud top to the ionosphere at $90 \mathrm{~km}$ altitude and can last up to $\sim 0.8 \mathrm{sec}[64,113-115]$. The observed gigantic jets were of negative polarity, produced by a normally electrified storm and therefore resembled to negative cloud-to-ionosphere discharges. Out of five gigantic jets, four events were found to be associated with ELF radio waves, while no cloud-to-ground lightning was observed to trigger these waves. This indicates that ELF waves were generated by negative cloud-to-ionosphere discharges. Each event reduces the ionospheric potential by removing 30 coulombs from the ionosphere [64], and their effect needs to be included in the GEC model.

3.2. DC Phenomena. In the atmospheric GEC, thunderstorms are thought to act as a giant battery distributed over the globe causing electric potentials up to $\pm 100 \mathrm{MeV}$ [74, $116]$, which are discharged in short $(\sim 1 \mathrm{~ms})$ time scales by cloud-to-ground or intracloud lightning. Even upward discharges like gigantic jets also discharge the GEC. Such large potentials could produce energetic photons, X-rays [117], and even gamma rays [118], which are absorbed in

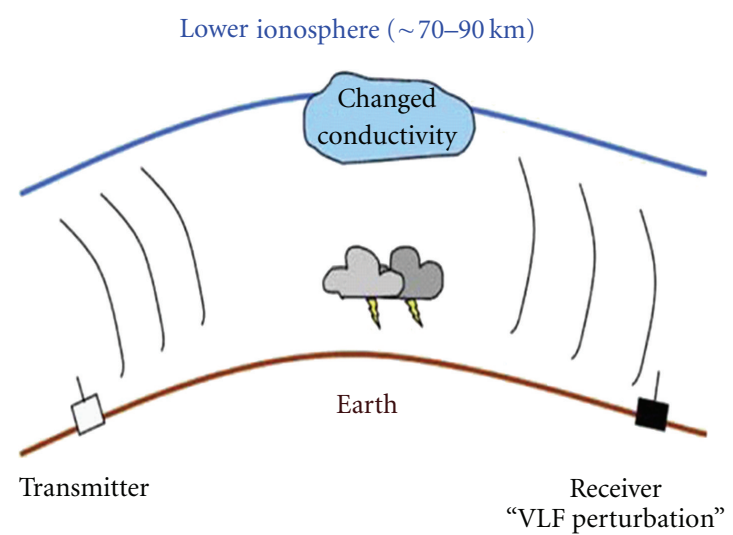

Figure 8: Diagram showing how the bottom side ionosphere and the mesosphere above a thunderstorm are probed by ground based transmitter, credit [40].

the short distance in the lower atmosphere but could travel appreciable distance before being absorbed in the middle and upper atmosphere.

The inherent current sources $[119,120]$ in the mesosphere may generate large DC electric fields in the $50-70 \mathrm{~km}$ region [121], which has been observed via rocket measurements $[122,123]$ and remotely via a series of MF radar measurements [124-127]. The large DC electric fields increase the electron temperature and effective collision frequency in D-region. The enhanced electron temperature over neutral temperature violates the local thermodynamic equilibrium. During the tropospheric disturbances, tropospheric conductivity increases and the electrical coupling between the troposphere and the mesosphere results in grounding the mesospheric current source and in a significant decrease in the intensity of large mesospheric electric fields. The electron temperature and effective collision frequency decrease, which results into the D-region cooling $[128,129]$.

The upward electric currents associated with the charge separation process for a single active thunderstorm are $\sim 1 \mathrm{~A}$. Assuming $\sim 1000$ thunderstorms operate at a time over the entire globe, there is an upward current of $\sim 1000 \mathrm{~A}$. Theses currents charge the highly conducting ionosphere ( $\sim 80 \mathrm{~km}$ altitude) to a potential of $\sim 250 \mathrm{kV}$ with respect to the Earth. The total charge on the plates of the Earthionosphere capacitor is $\sim 2 \times 10^{5} \mathrm{C}$ [59]. The electric currents $\left(\sim 2 \mathrm{pAm}^{-2}\right)$ flowing from the ionosphere to the Earth's surface remote from thunderstorms depend on the electrical conductivity of the medium. The conductivity may change due to the incident flux of cosmic rays, precipitation of energetic charged particles from the magnetosphere, changes in aerosol distribution, changes in the pressure, and the temperature distribution in the troposphere. The upward quasi-electrostatic fields also change the atmospheric/lower ionospheric conductivity. Figure 8 shows the measuring principles of the change in the electrical conductivity above thunderstorms in the mesosphere and the lower ionosphere by measuring changes in the amplitudes of signals radiating from narrow band radio transmitters passing over thunderstorms region [40]. Global warming affects 
distribution of aerosol, temperature, and concentration of gases in the troposphere and stratosphere and hence modifies the dynamics of the lower and the middle atmosphere [130]. These changes result into changes in thunderstorm and lightening properties. It would be interesting to study the changes produced in the GEC by the global warming phenomena.

In the study of electrical coupling of the atmosphere and the ionosphere, the latter is considered to be equipotential surface, which is not exactly true. During very active auroral conditions, the potential difference across the narrow $\left(1^{\circ}\right.$ or $2^{\circ}$ wide) auroral electrojet region may become $\sim 100 \mathrm{kV}$. Even ionospheric dynamos may create potential differences of $\sim 15-20 \mathrm{kV}$ between low and midlatitudes. These potential differences contradict the concept of the ionosphere as an equipotential surface. Ogawa et al. [131] have studied the variation of horizontal electric field in the middle atmosphere. The issue of equipotential further complicates because spatial and temporal variations of these potentials have a variety of scale lengths and various time scales. Intense atmospheric disturbances caused by earthquakes, volcanoes, tropical storms, typhoons, and so forth also affect electrical properties of the lower ionosphere. Some definite progresses in experimental and theoretical studies of man-made and natural effects on the ionosphere have been recently made [3]. However, there is significant gap in the understanding of an origin and interconnection of many processes involved in the atmosphere-ionosphere coupling.

\section{Summary}

The electrodynamic coupling between the Earth's atmosphere and the ionosphere is very complex and described by the global electric circuit. Currently, many aspects are not well understood. Recent measurements show that coupling influences both the electron density and electrical conductivity. Thunderstorms are the main generators situated in the troposphere. Measurements and theoretical studies have led to some understanding of charging mechanisms and charge structures of thunderstorms, however various aspects remain unanswered. Thunderstorms are large, complex, and short-lived phenomena; the charge generation and separation mechanism and charge structure are not known, and it is difficult to model them. The electrical processes are intimately related to the cloud dynamics or motions and to the microphysics of the clouds which are incompletely known or understood. Their detailed comprehension is essential as it controls climate and its variability. For proper understanding, it is essential to make simultaneous measurements of electric parameters from different parts of thunderstorms at small time intervals.

The role of transient luminous events on the local ionospheric potentials, modification of the electric field near the Earth's surface, and charging/discharging of GEC are yet to be quantified. Even there is dispute about the breakdown mechanism involved in the mesospheric discharges generating sprites, blue jets, elves, and so forth. Lightning-generated whistler mode waves cause precipitation of Van Allen belt electrons which modify D-region conductivity. The relative importance of different types of whistler mode waves is not known.

The generation of transient mesospheric electric field needs detailed study as it provides a basis for developing coupled troposphere-mesosphere-ionosphere electrodynamic models under disturbed conditions. In fact, numerous phenomena that occur in the upper atmosphere of the Earth are caused by the sources located in the lower atmosphere and on the ground such as thunderstorms, typhoons, dust storms, earthquakes, volcanic eruptions, and radioactive emissions from the nuclear power plants. All these phenomena affect the electrical conductivity from the Earth's surface to the lower ionosphere. Variation of conductivity and external current in the lower atmosphere lead to the perturbation of electric current flowing in the GEC and to the associated DC electric field perturbations both on the Earth's surface and in the ionosphere and hence affect the electrodynamic coupling of the Earth's atmosphere and the ionosphere.

\section{Acknowledgments}

A. K. Singh is thankful to DST for financial support. A. K. Singh, D. Siingh are also thankful to Indian Space Research Organization (ISRO) for partial financial support under CAWSES program. R. P. Singh acknowledges the facilities provided by the Head, Department of Physics, BHU, Varanasi, India.

\section{References}

[1] D. K. Singh, R. P. Singh, and A. K. Kamra, "The electrical environment of the earth's atmosphere: a review," Space Science Reviews, vol. 113, no. 3-4, pp. 375-408, 2004.

[2] T. Neubert, "Atmospheric science: on sprites and their exotic kin," Science, vol. 300, no. 5620, pp. 747-749, 2003.

[3] V. M. Sorokin and V. M. Chmyrev, "Atmosphere-Ionosphere Electrodynamic coupling," in The Atmosphere and Ionosphere, Physics of Earth and Space Environment, pp. 97-104, Springer, New York, NY, USA, 2010.

[4] E. S. Kazimirovsky, "Coupling from below as a source of ionospheric variability: a review," Annals of Geophysics, vol. 45, no. 1, pp. 1-30, 2002.

[5] T. B. Jones, K. Davies, and B. Wieder, "Observations of D-Region modifications at low and very low frequencies," Nature, vol. 238, no. 5358, pp. 33-34, 1972.

[6] R. J. Gamble, C. J. Rodger, M. A. Clilverd et al., "Radiation belt electron precipitation by man-made VLF transmissions," Journal of Geophysical Research A, vol. 113, no. 10, Article ID A10211, 2008.

[7] V. O. Rapoport, V. L. Frolov, G. P. Komrakov et al., "Some results of measuring the characteristics of electromagnetic and plasma disturbances stimulated in the outer ionosphere by high-power high-frequency radio emission from the "Sura" facility," Radiophysics and Quantum Electronics, vol. 50, no. 8, pp. 645-656, 2007.

[8] V. M. Sorokin, V. M. Chmyrev, and A. K. Yaschenko, "Electrodynamic model of the lower atmosphere and the ionosphere coupling," Journal of Atmospheric and Solar-Terrestrial Physics, vol. 63, pp. 1681-1691, 2001. 
[9] H. C. Chang and U. S. Inan, "Lightning-induce energetic electron precipitation from the magnetosphere," Journal of Geophysical Research, vol. 90, pp. 4531-4539, 1985.

[10] U. S. Inan, D. C. Shafer, W. Y. Yip, and R. E. Orville, "Subionospheric VLF signatures of nighttime D-region perturbations in the vicinity of lightning discharges," Journal of Geophysical Research, vol. 93, pp. 11455-11467, 1988.

[11] R. C. Moore, U. S. Inan, T. F. Bell, and E. J. Kennedy, "ELF waves generated by modulated HF heating of the auroral electrojet and observed at a ground distance of $4400 \mathrm{~km}$," Journal of Geophysical Research A, vol. 112, no. 5, Article ID A05309, 2007.

[12] V. L. Frolov, V. O. Rapoport, G. P. Komrakov et al., "Density ducts formed by heating the Earth's ionosphere with highpower HF radio waves," JETP Letters, vol. 88, no. 12, pp. 790794, 2008.

[13] G. M. Milikh, K. Papadopoulos, H. Shroff et al., "Formation of artificial ionospheric ducts," Geophysical Research Letters, vol. 35, no. 17, Article ID L17104, 2008.

[14] N. V. Dzhordzhio, M. M. Mogilevskii, V. M. Chmyrev et al., "Acceleration of ions in the plasma environment of the Earth by the radiation from a low-frequency transmitter on the ground," JETP Letters, vol. 46, pp. 405-409, 1987.

[15] H. L. Rowland, R. F. Ferseler, and P. F. Bernhardt, "Breakdown of the neutral atmosphere in the $\mathrm{D}$ region due to lightning driven electromagnetic pulses," Journal of Geophysical Research, vol. 101, pp. 7935-7945, 1996.

[16] V. P. Pasko, U. S. Inan, T. F. Bell, and Y. N. Taranenko, "Sprites produced by quasi-electrostatic heating and ionization in the lower ionosphere," Journal of Geophysical Research A, vol. 102, no. 3, Article ID 96JA03528, pp. 4529-4561, 1997.

[17] S. Fadnavis, D. Siingh, and R. P. Singh, "Mesospheric inversion layer and sprites," Journal of Geophysical Research D, vol. 114, no. 23, Article ID D23307, 2009.

[18] D. D. Sentman, E. M. Wescott, R. H. Picard et al., "Simultaneous observations of mesospheric gravity waves and sprites generated by a midwestern thunderstorm," Journal of Atmospheric and Solar-Terrestrial Physics, vol. 65, no. 5, pp. 537550, 2003.

[19] M. J. Heavner, Optical spectroscopic observations of sprites, blue jets, and elves: Inferred microphysical processes and their macrophysical implications, Ph.D. dissertation, University of Alaska Fairbanks, 2000.

[20] V. M. Sorokin, V. M. Chmyrev, and N. V. Isaev, "A generation model of small-scale geomagnetic field-aligned plasma inhomogeneities in the ionosphere," Journal of Atmospheric and Solar-Terrestrial Physics, vol. 60, no. 13, pp. 1331-1342, 1998.

[21] V. M. Chmyrev, V. M. Sorokin, and O. A. Pokhotelov, "Theory of small scale plasma density inhomogeneities and ULF/ELF magnetic field oscillations excited in the ionosphere prior to earthquakes," in Atmospheric and Ionospheric Electromagnetic Phenomena Associated with Earthquakes, M. Hayakawa, Ed., pp. 759-776, Terrapublication, Tokyo, Japan, 1999.

[22] M. Stolzenburg and T. C. Marshall, "Charge structure and dynamics in thunderstorms," Space Science Reviews, vol. 137, no. 1-4, pp. 355-372, 2008.

[23] Y. Yair, "Charge generation and separation processes," Space Science Reviews, vol. 137, no. 1-4, pp. 119-131, 2008.

[24] C. Saunders, "Charge separation mechanisms in clouds," Space Science Reviews, vol. 137, no. 1-4, pp. 335-353, 2008.

[25] E. Williams, M. Valente, E. Gerken, and R. Golka, "Calibrated radiance measurements with an air-field glow discharge tube: application to sprites in the mesosphere," in Sprites, Elves and
Intense Lightning Discharges, M. Fullekrug et al., Ed., vol. 225 of NATO Science Series, pp. 237-251, Springer, New York, NY, USA, 2006.

[26] M. J. Rycroft and M. Füllekrug, "The initiation and evolution of SPECIAL," Journal of Atmospheric and Solar-Terrestrial Physics, vol. 66, no. 13-14, pp. 1103-1113, 2004.

[27] K. L. Aplin, R. G. Harrison, and M. J. Rycroft, "Investigating earth's atmospheric electricity: a role model for planetary studies," Space Science Reviews, vol. 137, no. 1-4, pp. 11-27, 2008.

[28] M. J. Rycroft, "Electrical processes coupling the atmosphere and ionosphere: an overview," Journal of Atmospheric and Solar-Terrestrial Physics, vol. 68, no. 3-5, pp. 445-456, 2006.

[29] T. C. Marshall, M. Stolzenburg, C. R. Maggio et al., "Observed electric fields associated with lightning initiation," Geophysical Research Letters, vol. 32, no. 3, pp. 1-5, 2005.

[30] M. Stolzenburg, T. C. Marshall, W. D. Rust, E. Bruning, D. R. MacGorman, and T. Hamlin, "Electric field values observed near lightning flash initiations," Geophysical Research Letters, vol. 34, no. 4, Article ID L04804, 2007.

[31] A. V. Gurevich and K. P. Zybin, "Runaway breakdown and electric discharges in thunderstorms," Physics-Uspekhi, vol. 44, no. 11, pp. 1119-1140, 2001.

[32] A. V. Gurevich and K. P. Zybin, "Runaway breakdown and the mysteries of lightning," Physics Today, vol. 58, no. 5, pp. 37-43, 2005.

[33] A. V. Gurevich, G. G. Mitko, V. P. Antonova et al., "An intracloud discharge caused by extensive atmospheric shower," Physics Letters Section A, vol. 373, no. 39, pp. 3550-3553, 2009.

[34] M. A. Uman, The Lightning Discharge, Academic, Orlando, Fla, USA, 1987.

[35] D. D. Sentman and E. M. Wescott, "Observations of upper atmospheric optical flashes recorded from an aircraft," Geophysical Research Letters, vol. 20, no. 24, pp. 2857-2860, 1993.

[36] C. Haldoupis, R. J. Steiner, A. Mika et al., "“Early/slow" events: a new category of VLF perturbations observed in relation with sprites," Journal of Geophysical Research A, vol. 111, no. 11, Article ID A11321, 2006.

[37] L. Liszka, "On the possible infrasound generation by sprites," Journal of Low Frequency Noise Vibration and Active Control, vol. 23, no. 2, pp. 85-93, 2004.

[38] L. Liszka and Y. Hobara, "Sprite-attributed infrasonic chirpstheir detection, occurrence and properties between 1994 and 2004," Journal of Atmospheric and Solar-Terrestrial Physics, vol. 68, no. 11, pp. 1179-1188, 2006.

[39] T. Farges, E. Blanc, A. Le Pichon, T. Neubert, and T. H. Allin, "Identification of infrasound produced by sprites during the Sprite2003 campaign," Geophysical Research Letters, vol. 32, no. 1, pp. 1-4, 2005.

[40] T. Neubert, M. Rycroft, T. Farges et al., "Recent results from studies of electric discharges in the mesosphere," Surveys in Geophysics, vol. 29, no. 2, pp. 71-137, 2008.

[41] S. B. Mende, H. U. Frey, R. R. Hsu et al., "D region ionization by lightning-induced electromagnetic pulses," Journal of Geophysical Research A, vol. 110, no. 11, Article ID A11312, 2005.

[42] Z. Cheng, S. A. Cummer, H. T. Su, and R. R. Hsu, "Broadband very low frequency measurement of $\mathrm{D}$ region ionospheric perturbations caused by lightning electromagnetic pulses," Journal of Geophysical Research A, vol. 112, no. 6, Article ID A06318, 2007.

[43] C. Haldoupis, N. Amvrosiadi, B. R. T. Cotts, O. A. van der Velde, O. Chanrion, and T. Neubert, "More evidence for 
a one-to-one correlation between Sprites and Early VLF perturbations," Journal of Geophysical Research, vol. 115, p. A07304, 2010.

[44] C. Haldoupis, A. Mika, and S. Shalimov, "Modeling the relaxation of early VLF perturbations associated with transient luminous events," Journal of Geophysical Research A, vol. 114, no. 10, Article ID A00E04, 2009.

[45] A. Mika, Very low frequency EM wave studies of transient luminous events in the lower ionosphere, Ph.D. thesis, University of Crete, 2007.

[46] Y. N. Taranenko, U. S. Inan, and T. F. Bell, "Interaction with the lower ionosphere of electromagnetic pulses from lightning: heating, attachment, and ionization," Geophysical Research Letter, vol. 20, pp. 1539-1542, 1993.

[47] H. L. Rowland, "Theories and simulations of elves, sprites and blue jets," Journal of Atmospheric and Solar-Terrestrial Physics, vol. 60, no. 7-9, pp. 831-844, 1998.

[48] Y. Hiraki, T. Lizhu, H. Fukunishi, K. Nambu, and H. Fujiwa, "Development of a new numerical model for investigation the energetic of sprites," Eos Transactions of American Geophysical Union, vol. 83, no. 47, 2002.

[49] J. M. Galloway, F. J. Dentener, D. G. Capone et al., "Nitrogen cycles: past, present and future," Biogeochemistry, vol. 70, pp. 153-226, 2004.

[50] D. Siingh, R. P. Singh, A. K. Kamra et al., "Review of electromagnetic coupling between the Earth's atmosphere and the space environment," Journal of Atmospheric and SolarTerrestrial Physics, vol. 67, no. 6, pp. 637-658, 2005.

[51] U. Schumann and H. Huntrieser, "The global lightninginduced nitrogen oxides source," Atmospheric Chemistry and Physics, vol. 7, no. 14, pp. 3823-3907, 2007.

[52] P. J. Crutzen, "Photochemical reactions initiated by and influencing ozone in unpolluted tropospheric air," Tellus, vol. 26, pp. 47-57, 1974.

[53] W. C. Burgess and U. S. Inan, "The role of ducted whistlers in the precipitation loss and equilibrium flux of radiation belt electrons," Journal of Geophysical Research, vol. 98, pp. 15643-15650, 1993.

[54] T. J. Rosenberg, R. A. Helliwell, and J. P. Katsufrakis, "Electron precipitation associated with discrete very low frequency emissions," Journal of Geophysical Research, vol. 76, p. 8445, 1971.

[55] M. J. Rycroft, "Enhanced energetic electron intensities at $100 \mathrm{~km}$ altitude and a whistler propagating through the plasmasphere," Planetary and Space Science, vol. 21, no. 2, pp. 239-251, 1973.

[56] R. J. Goldberg, S. A. Curtis, and J. R. Barcus, "Detailed spectral structure of magnetospheric electron bursts precipitated by lightning," Journal of Geophysical Research, vol. 92, pp. 2505-2512, 1987.

[57] H. D. Voss, W. L. Imhof, M. Walt et al., "Lightning-induced electron precipitation," Nature, vol. 312, no. 5996, pp. 740 $742,1984$.

[58] H. D. Voss, "Satellite observations of lightning-induced electron precipitation," Journal of Geophysical Research A, vol. 103, no. 6, Article ID 97JA02878, pp. 11725-11744, 1998.

[59] M. J. Rycroft, S. Israelsson, and C. Price, "The global atmospheric electric circuit, solar activity and climate change," Journal of Atmospheric and Solar-Terrestrial Physics, vol. 62, no. 17-18, pp. 1563-1576, 2000.

[60] E. R. Williams and S. J. Heckman, "The local diurnal variation of cloud electrification and the global diurnal variation of negative charge on the Earth," Journal of Geophysical Research, vol. 98, no. 3, pp. 5221-5234, 1993.
[61] M. J. Rycroft, A. Odzimek, N. F. Arnold, M. Füllekrug, A. Kułak, and T. Neubert, "New model simulations of the global atmospheric electric circuit driven by thunderstorms and electrified shower clouds: the roles of lightning and sprites," Journal of Atmospheric and Solar-Terrestrial Physics, vol. 69, no. 17-18, pp. 2485-2509, 2007.

[62] C. L. Ziegler and D. R. Macgorman, "Observed lightning morphology relative to modeled space charge and electric field distributions in a tornadic storm," Journal of the Atmospheric Sciences, vol. 51, no. 6, pp. 833-851, 1994.

[63] V. P. Pasko, “Electric jets," Nature, vol. 423, no. 6943, pp. 927929, 2003.

[64] H. T. Su, R. R. Hsu, A. B. Chen et al., "Gigantic jets between a thundercloud and the ionosphere," Nature, vol. 423, no. 6943, pp. 974-976, 2003.

[65] Y. P. Raizer, G. M. Milikh, and M. N. Shneider, "On the mechanism of blue jet formation and propagation," Geophysical Research Letters, vol. 33, no. 23, Article ID L23801, 2006.

[66] Y. P. Raizer, G. M. Milikh, and M. N. Shneider, "Leaderstreamers nature of blue jets," Journal of Atmospheric and Solar-Terrestrial Physics, vol. 69, no. 8, pp. 925-938, 2007.

[67] M. Johnston, "Electromagnetic fields generated by earthquakes," in International Handbook of Earthquake and Engineering Seismology, W. Lee, H. Kanamori, P. Jennings, and C. Kisslinger, Eds., part A, pp. 621-634, Academic Press, 2002.

[68] M. Parrot, "Statistical study of ELF/VLF emissions recorded by a low-altitude satellite during seismic events," Journal of Geophysical Research, vol. 99, pp. 23339-23347, 1994.

[69] V. A. Liperovsky, O. A. Pokhotelov, C. V. Meister, and E. V. Liperovskaya, "Physical models of coupling in the lithosphere-atmosphere-ionosphere system before earthquakes," Geomagnetism and Aeronomy, vol. 48, no. 6, pp. 795-806, 2008.

[70] N. F. Arnold and T. R. Robinson, "Solar cycle changes to planetary wave propagation and their influence on the middle atmosphere circulation," Annales Geophysicae, vol. 16, no. 1, pp. 69-76, 1998.

[71] S. A. Bowhill, "Interaction between the stratosphere and ionosphere," Annals of the International Year of the Quiet Sun, vol. 5, pp. 83-95, 1969.

[72] P. R. Krehbiel, J. A. Riousset, V. P. Pasko et al., "Upward electrical discharges from thunderstorms," Nature Geoscience, vol. 1, no. 4, pp. 233-237, 2008.

[73] T. C. Marshall, M. Stolzenburg, P. R. Krehbiel, N. R. Lund, and C. R. Maggio, "Electrical evolution during the decay stage of New Mexico thunderstorms," Journal of Geophysical Research D, vol. 114, no. 2, Article ID D02209, 2009.

[74] V. A. Rakov and M. A. Uman, Lightning: Physics and Effects, Cambridge University Press, Cambridge, UK, 2003.

[75] M. Stolzenburg, "Observations of high ground flash densities of positive lightning in summertime thunderstorms," Monthly Weather Review, vol. 122, no. 8, pp. 1740-1750, 1994.

[76] M. Stolzenburg, W. D. Rust, B. F. Smull, and T. C. Marshall, "Electrical structure in thunderstorm convective regions 1. Mesoscale convective systems," Journal of Geophysical Research D, vol. 103, no. 12, pp. 14059-14078, 1998.

[77] W. D. Rust, D. R. MacGorman, E. C. Bruning et al., "Inverted-polarity electrical structures in thunderstorms in the Severe Thunderstorm Electrification and Precipitation Study (STEPS)," Atmospheric Research, vol. 76, no. 1-4, pp. 247-271, 2005. 
[78] D. Siingh, V. Gopalakrishnan, R. P. Singh et al., "The atmospheric global electric circuit: an overview," Atmospheric Research, vol. 84, no. 2, pp. 91-110, 2007.

[79] R. G. Roble and L. Tzur, "The global atmospheric-electrical circuit," in The Earth's Electrical Environment, pp. 206-231, National Academy Press, Washington, DC, USA, 1986.

[80] S. S. Davydenko, E. A. Mareev, T. C. Marshall, and M. Stolzenburg, "On the calculation of electric fields and currents of mesoscale convective systems," Journal of Geophysical Research D, vol. 109, no. 11, pp. D11103-10, 2004.

[81] R. G. Harrison and K. S. Carslaw, "Ion-aerosol-cloud processes in the lower atmosphere," Reviews of Geophysics, vol. 41, no. 3, pp. 2-1, 2003.

[82] W. O. Schumann, "U' ber die strahlunglosen eigenschwingungen einer leitenden Kugel, die von einer Luftschicht und einer Ionospharenh ulle umgeben ist," Zeitschrift Naturforschung, vol. 7, pp. 6627-6628, 1952.

[83] E. Huang, E. Williams, R. Boldi et al., "Criteria for sprites and elves based on Schumann resonance observations," Journal of Geophysical Research D, vol. 104, no. 14, pp. 16943-16964, 1999.

[84] E. Greenberg, C. Price, Y. Yair, M. Ganot, J. Bór, and G. Sátori, "ELF transients associated with sprites and elves in eastern Mediterranean winter thunderstorms," Journal of Atmospheric and Solar-Terrestrial Physics, vol. 69, no. 13, pp. 1569-1586, 2007.

[85] E. Greenberg, C. Price, Y. Yair, C. Haldoupis, O. Chanrion, and T. Neubert, "ELF/VLF signatures of sprite-producing lightning discharges observed during the 2005 EuroSprite campaign," Journal of Atmospheric and Solar-Terrestrial Physics, vol. 71, no. 12, pp. 1254-1266, 2009.

[86] R. A. Helliwell, "40 years of whistlers," in Modern Radio Science, pp. 189-212, Oxford University Press, New York, NY, USA, 1993.

[87] C. J. Rodger, "Subionospheric VLF perturbations associated with lightning discharges," Journal of Atmospheric and SolarTerrestrial Physics, vol. 65, no. 5, pp. 591-606, 2003.

[88] U. S. Inan, S. A. Cummer, and R. A. Marshall, "A survey of ELF and VLF research on lightning-ionosphere interactions and causative discharges," Journal of Geophysical Research A, vol. 115, no. 6, Article ID A00E36, 2010.

[89] M. Hayakawa, "Association of whistlers with lightning discharges on the Earth and on Jupiter," Journal of Atmospheric and Terrestrial Physics, vol. 57, no. 5, pp. 525-535, 1995.

[90] M. J. Rycroft, "Interactions between whistler-mode waves and energetic electrons in the coupled system formed by the magnetosphere, ionosphere and atmosphere," Journal of Atmospheric and Terrestrial Physics, vol. 53, no. 9, pp. 849$858,1991$.

[91] A. Mika, C. Haldoupis, R. A. Marshall, T. Neubert, and U. S. Inan, "Subionospheric VLF signatures and their association with sprites observed during EuroSprite-2003," Journal of Atmospheric and Solar-Terrestrial Physics, vol. 67, no. 16, pp. 1580-1597, 2005.

[92] A. K. Singh, "Ultra low frequency waves," in Solar Terrestrial Environment: Space Weather, R. P. Singh, R. Singh, and A. K. Singh, Eds., pp. 429-440, Allied, New Delhi, India, 2003.

[93] P. P. Belyaev, S. V. Polyakov, V. O. Rapoport, and V. Y. Trakhtengerts, "The ionospheric Alfven resonator," Journal of Atmospheric and Terrestrial Physics, vol. 52, no. 9, pp. 781$788,1990$.

[94] A. I. Sukhorukov and P. Stubbe, "Problems of blue jet theories," Journal of Atmospheric and Solar-Terrestrial Physics, vol. 60, no. 7-9, pp. 725-732, 1998.
[95] P. P. Belyaev, S. V. Polyakov, E. N. Ermakova, and S. V. Isaev, "Solar cycle variations in the ionospheric Alfven resonator 1985-1995," Journal of Atmospheric and Solar-Terrestrial Physics, vol. 62, no. 4, pp. 239-248, 2000.

[96] G. A. Mikhailova, Y. M. Mikhailov, and O. V. Kapustina, "ULF-VLF electric fields in the external ionosphere over powerful typhoons in Pacific Ocean," International Journal of Geomagnetism and Aeronomy, vol. 2, no. 2, 2000.

[97] V. P. Pasko, U. S. Inan, Y. N. Taranenko, and T. F. Bell, "Heating, ionization and upward discharges in the mesosphere due to intense quasi-electrostatic thunderstorm fields," Geophysical Research Letter, vol. 22, pp. 365-370, 1995.

[98] C. J. Rodger, M. Cho, M. A. Clilverd, and M. J. Rycroft, "Lower ionospheric modification by lightning-EMP: simulation of the night ionosphere over the United States," Geophysical Research Letters, vol. 28, no. 2, pp. 199-202, 2001.

[99] U. S. Inan, "VLF heating of the lower ionosphere," Geophysical Research Letters, vol. 17, pp. 729-732, 1990.

[100] P. Stubbe, "Review of ionospheric modification experiments at Tromsø," Journal of Atmospheric and Terrestrial Physics, vol. 58, no. 1-4, pp. 349-368, 1996.

[101] V. P. Pasko, U. S. Inan, and T. F. Bell, "Sprites as luminous columns of ionization produced by quasi-electrostatic thundercloud fields," Geophysical Research Letters, vol. 23, no. 6, pp. 649-652, 1996.

[102] M. Cho and M. J. Rycroft, "Computer simulation of the electric field structure and optical emission from cloudtop to the ionosphere," Journal of Atmospheric and SolarTerrestrial Physics, vol. 60, no. 7-9, pp. 871-888, 1998.

[103] L. P. Babich, A. Y. Kudryavtsev, M. L. Kudryavtseva, and I. M. Kutsyk, "Atmospheric gamma-ray and neutron flashes," Journal of Experimental and Theoretical Physics, vol. 106, no. 1, pp. 65-76, 2008.

[104] M. Füllekrug, R. Roussel-Dupré, E. M. D. Symbalisty et al., "Relativistic runaway breakdown in low-frequency radio," Journal of Geophysical Research A, vol. 115, no. 1, Article ID A00E09, 2010.

[105] O. Chanrion and T. Neubert, "Production of runaway electrons by negative streamer discharges," Journal of Geophysical Research A, vol. 115, no. 6, Article ID A00E32, 2010.

[106] E. Gerken and U. Inan, "Streamers and diffuse glow observed in upper atmospheric electrical discharges," IEEE Transactions on Plasma Science, vol. 33, no. 2 I, pp. 282-283, 2005.

[107] T. Adachi, H. Fukunishi, Y. Takahashi, and M. Sato, "Roles of the EMP and QE field in the generation of columniform sprites," Geophysical Research Letters, vol. 31, no. 4, pp. L04107-4, 2004.

[108] O. A. van der Velde, A. Mika, S. Soula, C. Haldoupis, T. Neubert, and U. S. Inan, "Observations of the relationship between sprite morphology and in-cloud lightning processes," Journal of Geophysical Research D, vol. 111, no. 15, Article ID D15203, 2006.

[109] N. Liu and V. P. Pasko, "Effects of photoionization on propagation and branching of positive and negative streamers in sprites," Journal of Geophysical Research A, vol. 109, Article ID A04301, 2004.

[110] J. Qin, S. Celestin, and V. P. Pasko, "On the inception of streamers from sprite halo events produced by lightning discharges with positive and negative polarity," Journal of Geophysical Research A, vol. 116, Article ID A06305, 2011.

[111] V. P. Pasko and J. J. George, "Three-dimensional modeling of blue jets and blue starters," Journal of Geophysical Research A, vol. 107, Article ID 1458, 2002. 
[112] V. P. Pasko, M. A. Stanley, J. D. Mathews, U. S. Inan, and T. G. Wood, "Electrical discharge from a thundercloud top to the lower ionosphere," Nature, vol. 416, no. 6877, pp. 152-154, 2002.

[113] C. L. Kuo, A. B. Chen, Y. J. Lee et al., "Modeling elves observed by FORMOSAT-2 satellite," Journal of Geophysical Research A, vol. 112, no. 11, Article ID A11312, 2007.

[114] C. L. Kuo, J. K. Chou, L. Y. Tsai et al., "Discharge processes, electric field, and electron energy in ISUAL recorded gigantic jets," Journal of Geophysical Research A, vol. 114, no. 4, Article ID A04314, 2009.

[115] S. A. Cummer, J. Li, F. Han et al., "Quantification of the troposphere-to-ionosphere charge transfer in a gigantic jet," Nature Geoscience, vol. 2, no. 9, pp. 617-620, 2009.

[116] V. I. Ermakov and Y. I. Stozhkov, Thunderstorm Cloud Physics, Lebedev Physical Institute, Russian Academy of Sciences, 2004.

[117] M. P. McCarthy and G. K. Parks, "On the modulation of X ray fluxes in thunderstorms," Journal of Geophysical Research, vol. 97, no. 5, pp. 5857-5864, 1992.

[118] G. J. Fishman, P. N. Bhat, R. Mallozzi et al., "Discovery of intense gamma-ray flashes of atmospheric origin," Science, vol. 264, no. 5163, pp. 1313-1316, 1994.

[119] A. C. Aikin and N. C. Maynard, "A Van de Graaf source mechanism for middle atmospheric vertical electric fields," Journal of Atmospheric and Terrestrial Physics, vol. 52, no. 9, pp. 695-705, 1990.

[120] S. V. Polyakov, V. O. Rapoport, and V. Y. Trakhtengerts, "the generation of electric fields in the upper atmosphere," Geomagnetism Aeronomy, vol. 30, p. 869, 1990.

[121] R. A. Goldberg, "Middle atmospheric electrodynamics during map," Advances in Space Research, vol. 10, no. 10, pp. 209217, 1990.

[122] M. C. Kelley, C. L. Siefring, and R. F. Pfaff Jr., "Large middle atmospheric electric fields, fact or fiction?" Geophysical Research Letter, vol. 10, p. 733, 1983.

[123] A. M. Zadorozhny and A. A. Tyutin, "Effects of geomagnetic activity on the mesospheric electric fields," Annales Geophysicae, vol. 16, no. 12, pp. 1544-1551, 1998.

[124] A. M. Gokov and S. I. Martynenko, "Changes in the electron collision frequency and electric field in the lower ionosphere," Geomagnetism Aeronomy, vol. 37, p. 76, 1997.

[125] S. I. Martynenko, V. T. Rozumenko, A. M. Tsymbal, O. F. Tyrnov, and A. M. Gokov, "Mesospheric electric field measurements with a partial reflection radar," Journal Atmospheric Electricity, vol. 19, p. 81, 1999.

[126] S. I. Martynenko, V. T. Rozumenko, and O. F. Tyrnov, "New possibilities for mesospheric electricity diagnostics," Advances in Space Research, vol. 27, no. 6-7, pp. 1127-1132, 2001.

[127] C. E. Meek, A. H. Manson, S. I. Martynenko, V. T. Rozumenko, and O. F. Tyrnov, "Remote sensing of mesospheric electric fields using MF radars," Journal of Atmospheric and Solar-Terrestrial Physics, vol. 66, no. 10, pp. 881-890, 2004.

[128] I. M. Fuks, R. S. Shubova, and S. I. Martynenko, "Lower ionosphere response to conductivity variations of the near-earth atmosphere," Journal of Atmospheric and Solar-Terrestrial Physics, vol. 59, no. 9, pp. 961-965, 1997.

[129] S. I. Martynenko and S. F. Clifford, "On the electrical coupling between the troposphere and the mesosphere," International Journal of Geomagnetism and Aeronomy, vol. 6, Article ID GI2007, 2006.

[130] D. Siingh, R. P. Singh, A. K. Singh, M. N. Kulkarni, A. S. Gautam, and A. K. Singh, "Solar activity, lightning and climate," Surveys in Geophysics, vol. 32, no. 6, pp. 659-703, 2011.
[131] T. Ogawa, Y. Tanaka, A. Huzita, and M. Yasuhara, "Horizontal electric fields in the middle latitude," Planetary and Space Science, vol. 23, no. 5, pp. 825-830, 1975. 

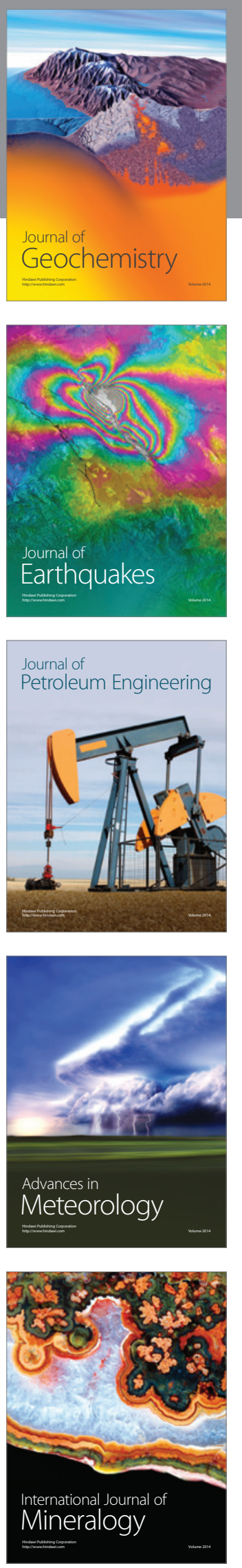
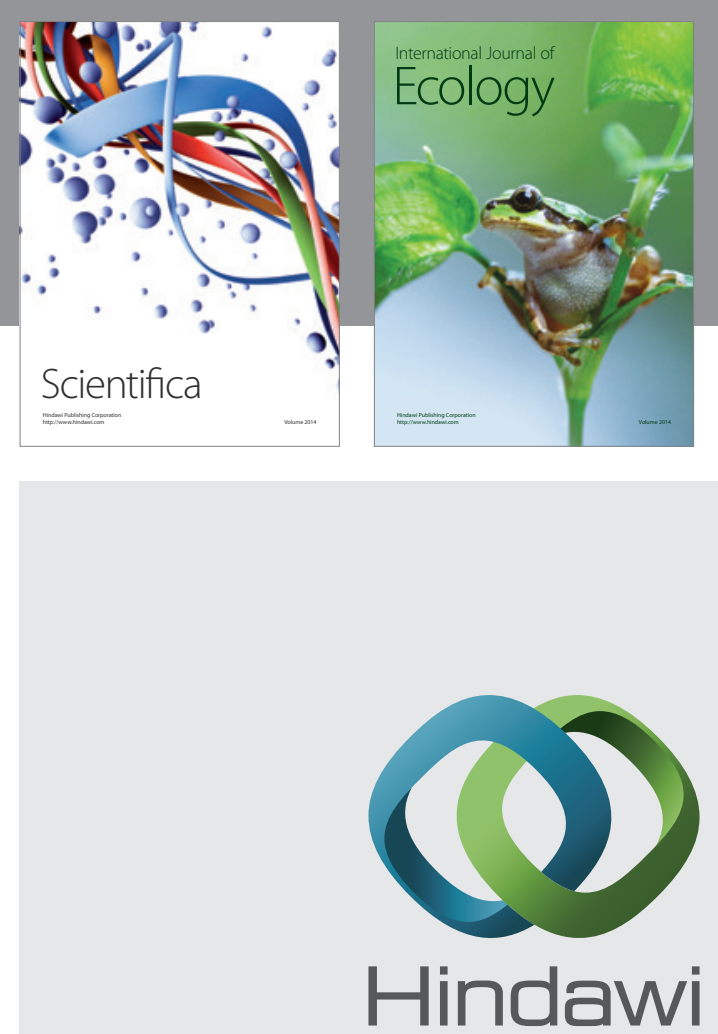

Submit your manuscripts at http://www.hindawi.com
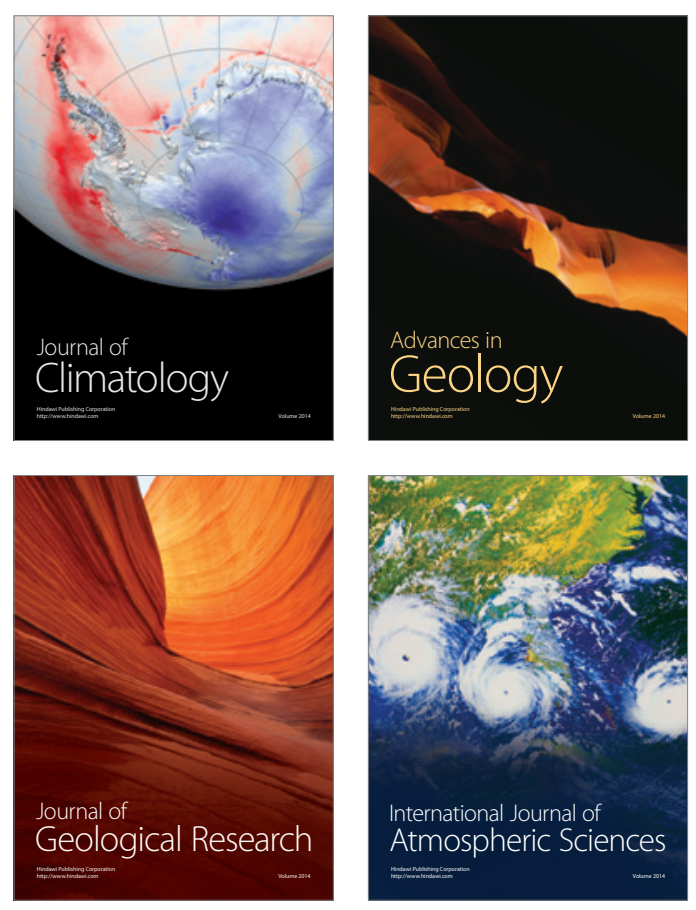
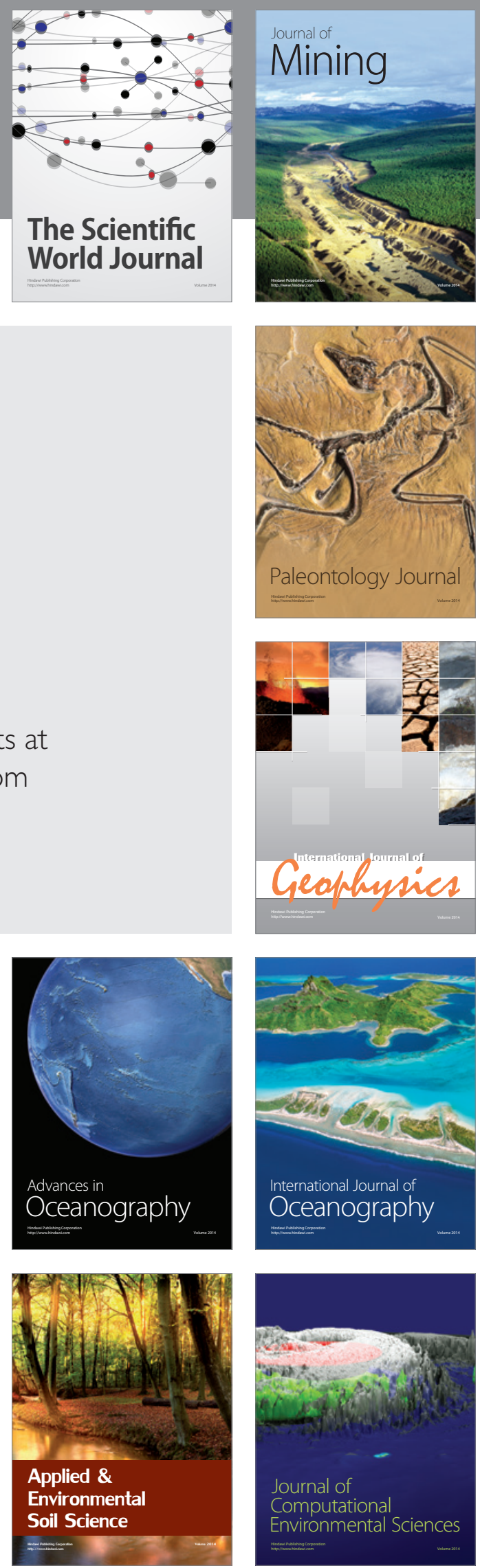